\title{
UNA NUEVA SENTENCIA DEL TJUE SOBRE EL CONCEPTO \\ DE RESIDENCIA HABITUAL EN EL MARCO DEL REGLAMENTO 2201/2003: SENTENCIA DE 17 DE OCTUBRE DE 2018, UD Y XB, AS. 393/18 PPU
}

\author{
A NEW ECJ JUDGMENT ABOUT THE CONCEPT \\ OF HABITUAL RESIDENCE IN THE FRAMEWORK OF \\ REGULATION 2201/2003: JUDGMENT 17 OCTOBER 2018, \\ UD V. XB, C. 393/18
}

\author{
Beatriz Campuzano díaz \\ Profesora Titular de Derecho Internacional Privado \\ Universidad de Sevilla \\ ORCID ID: 0000-0001-9737-5316
}

Recibido: 17.06.2019 / Aceptado: 18.07.2019

DOI: https://doi.org/10.20318/cdt.2019.4972

\begin{abstract}
Resumen: Esta sentencia se refiere a la interpretación del art. 8 del Reglamento 2201/2003. La cuestión prejudicial la formuló un tribunal inglés en un procedimiento entre UD y XB, madre y padre de una menor nacida en Bangladés. Se cuestionó si la presencia física de la menor en el Reino Unido constituía un elemento necesario del concepto de residencia habitual, dado que nunca había estado en este país. La cuestión se formuló en un contexto muy particular, pues la menor nació en Bangladés debido a que la madre, supuestamente, estaba siendo retenida bajo coacción en este país por el padre.

Palabras clave: residencia habitual, menor lactante, madre retenida bajo coacción en un tercer Estado.

Abstract: This judgment refers to the interpretation of Article 8 of Regulation 2201/2003. The request for the preliminary ruling was made by an English court in a proceeding between UD and XB, mother and father of an infant, born in Bangladesh. The English court questioned whether physical presence was an intrinsic element of the concept of habitual residence, as the girl had never been in The United Kingdom. This question was made in a very particular context, as the child was born in Bangladesh because the mother, supposedly, was being kept through coercion in that country by the father.

Keywords: habitual residence, infant, mother kept through coercion in a third State.

Sumario: I. Presentación de la Sentencia del TJUE de 17 de octubre de 2018, UD y XB, as. 393/18 PPU. 1. Los hechos. 2. Las cuestiones que se formulan. II. Análisis de la Sentencia del TJUE de 17 de octubre de 2018, UD y XB, as. 393/18 PPU. 1. La aplicación del Reglamento 2201/2003 en las situaciones conectadas con terceros Estados. 2. La jurisprudencia del TJUE sobre el concepto de residencia habitual en el marco del Reglamento 2201/2203. 3. La presencia física del menor en un Estado miembro como elemento configurador del foro general de la residencia habitual.
\end{abstract}




\section{Presentación de la Sentencia del TJUE de 17 de octubre de 2018, UD y XB, as. 393/18 PPU1.}

1. La Sentencia objeto de comentario se dicta a raíz de una cuestión prejudicial planteada por la High Court of Justice (England and Wales), Family Division [Tribunal Superior de Justicia (Inglaterra y Gales), División de familia, Reino Unido], mediante resolución de 6 de junio de 2018, en el marco de un litigio entre UD y XB, madre y padre de una menor nacida en Bangladés, el 2 de febrero de 2017.

2. La petición de decisión prejudicial tiene por objeto la interpretación del artículo 8 del Reglamento (CE) N 2201/2003 del Consejo, de 27 de noviembre de 2003, relativo a la competencia, el reconocimiento y la ejecución de resoluciones judiciales en materia matrimonial y de responsabilidad parental, por el que se deroga el Reglamento (CE) N $\mathrm{N}^{\circ}$ 1347/2000. Esta cuestión prejudicial se ha tramitado a través del procedimiento de urgencia, conforme a lo dispuesto en el art. 107 del Reglamento de Procedimiento del Tribunal de Justicia.

\section{Los hechos}

3. La demandante en el litigio principal, madre de la menor, es nacional de Bangladés, y contrajo matrimonio en 2013, en ese mismo país, con el demandado en el litigio principal, de nacionalidad británica, padre de la menor. La madre y el padre son identificados en el texto de la Sentencia con las iniciales UD y XB, respectivamente.

4. En 2016 la madre se estableció en el Reino Unido con el fin de residir en dicho Estado miembro con el padre, gracias a un visado para cónyuge extranjero expedido por el United Kingdom Home Office. En la narración de los hechos se deja abierta la fecha en que ello se produjo, junio o julio de 2016, aunque sí se precisa que la validez del visado se extendía desde el 1 de julio de 2016 hasta el 1 de abril de 2019.

5. En diciembre de 2016 el padre y la madre viajaron a Bangladés, encontrándose la madre en ese momento en avanzado estado de gestación. El 2 de febrero de 2017 la menor nació en Bangladés y desde entonces permanece en ese país sin haber residido nunca en el Reino Unido. En enero de 2018 el padre volvió al Reino Unido sin la madre.

6. El 20 de marzo de 2018 la madre presentó una demanda ante el órgano jurisdiccional remitente -High Court of Justice (England and Wales), Family Division-, solicitando que la menor fuera colocada bajo la tutela de este órgano jurisdiccional y que se ordenara el retorno de ambas al Reino Unido con el fin de participar en el procedimiento. Según la madre este órgano jurisdiccional era competente para resolver el litigio, dado que en la fecha de presentación de la demanda la menor residía habitualmente en el Reino Unido. El padre se opuso.

7. En estas circunstancias, la High Court of Justice (England and Wales), Family Division, señaló que el concepto de "residencia habitual" sigue suscitando cuestiones que aún no han sido examinadas por el Tribunal de Justica, en particular, si la presencia física del menor en un Estado miembro constituye un elemento configurador necesario de este concepto. Para reforzar el sentido de la pregunta se añadió que fueron las supuestas presiones ejercidas por el padre sobre la madre las que llevaron a que esta diera a luz en un país tercero, donde los progenitores no tenían la intención común de residir, lo cual podía haber constituido una vulneración de los derechos de la madre y de la menor.

\section{Las cuestiones que se formulan.}

8. La High Court of Justice (England and Wales), Family Division planteó las siguientes cuestiones prejudiciales: "1) ¿Constituye la presencia física de un menor en un Estado un elemento esencial

${ }^{1}$ ECLI:EU:C:2018:835 
de la residencia habitual, en el sentido del artículo 8 del Reglamento $N^{\circ}$ 2201/2003? 2) Cuando ambos progenitores son titulares de la responsabilidad parental, ¿influye el hecho de que la madre fuera inducida mediante engaño a trasladarse a otro Estado, en el que fue retenida ilícitamente por el padre mediante presiones u otro acto ilegal, viéndose así obligada a dar a luz a un hijo en ese Estado, en la respuesta que ha de darse a la primera cuestión prejudicial en circunstancias en las que pudo existir una vulneración de los [derechos] de la madre o del hijo conforme a los artículos 3 y 5 del [Convenio Europeo para la Protección de los Derechos Humanos y de las Libertades Fundamentales, firmado en Roma el 4 de noviembre de 1950], o por otros motivos?".

\section{Análisis de la Sentencia del TJUE de 17 de octubre de 2018, UD y XB, as. 393/18 PPU}

\section{La aplicación del Reglamento 2201/2003 en las situaciones conectadas con terceros Estados}

9. Una primera cuestión que se plantea en la Sentencia objeto de comentario es la pretensión del Gobierno del Reino Unido de impugnar la competencia del TJUE para responder a las cuestiones planteadas, con el argumento de que el asunto versa sobre un potencial conflicto de competencia entre un Estado miembro, Reino Unido, y un Estado tercero, Bangladés. Según este Gobierno, como el Reglamento 2201/2003 se adoptó sobre la base de los arts. 61.c) y 67.1 TCE, se aplica únicamente a las situaciones transfronterizas que se dan en el interior de la Unión, debiéndose acudir al derecho nacional cuando se trata de situaciones transfronterizas conectadas con un Estado tercero (pp. 29 y 30).

10. La verdad es que esta pretensión nos trae recuerdos del pasado. El Reglamento 2201/2003 se adoptó efectivamente sobre la base de los mencionados preceptos del TCE, que se referían a la actuación de las instituciones europeas en el ámbito de la cooperación judicial en materia civil con repercusión transfronteriza, en la medida necesaria para el correcto funcionamiento del mercado interior. En relación con estos preceptos se planteó un debate a nivel doctrinal, que fue especialmente intenso en Francia y el Reino Unido, sobre si la UE podía estar actuando más allá de sus competencias cuando aprobaba normas que se aplicaban a situaciones con repercusión transfronteriza, pero que no estaban vinculadas con el correcto funcionamiento del mercado interior, por afectar a terceros Estados ${ }^{2}$. Ese debate se zanjó con el Tratado de Lisboa. En el art. 81 TFUE se establece que la UE desarrollará una cooperación judicial en asuntos civiles con repercusión transfronteriza, en particular cuando resulte necesario para el buen funcionamiento del mercado interior, aclarándose así que el mercado interior se entiende como una prioridad que no impide contemplar situaciones que vayan más allá del mismo³.

11. Pero, antes incluso de este cambio normativo, contábamos con antecedentes jurisprudenciales que deberían haber hecho dudar al Gobierno británico de la pretensión de impugnar la competencia del TJUE. Nos referimos, concretamente, a la famosa Sentencia del TJCE de 1 de marzo de 2005, C-281/02, Owusu ${ }^{4}$, donde, también por parte del Gobierno del Reino Unido, se cuestionó que pudiera aplicarse el Convenio de Bruselas de 1968 para determinar la competencia judicial internacional de los tribunales ingleses, en un supuesto estrechamente vinculado con un tercer Estado. El TJCE se pronunció de forma favorable a su aplicación, por tratarse de un supuesto en que el demandado estaba domiciliado en un Estado miembro y en el que se cumplían los requisitos para la aplicación del Convenio de Bruselas.

\footnotetext{
${ }^{2}$ Al respecto vid. I. Barriere Brousse, "Le Traité de Lisbonne et le Droit international privé", Journal du Droit International, 2010, № 1, págs. 8-9; J. HARRIs, "Understanding the English Response to the Europeanisation of Private International Law”, Journal of Private International Law, 2008, Vol. 4, № 3, págs. 357-359.

${ }^{3}$ Para un análisis de los cambios introducidos por el Tratado de Lisboa, vid. I. BARRIERE Brousse, "Le Traité de Lisbonne et le droit international privé", op. cit., págs. 3 y ss.; F. PAulino Pereira, "La coopération judiciaire en matière civile dans l'Union Europénne: bilan et perspectives", Revue Critique de Droit International Privé, 2010, Vol. 99, No 1, págs. 1 y ss.

${ }^{4}$ ECLI:EU:C:2005:120, nota de C. Otero García-CASTrillón, en Revista española de derecho internacional, 2005, pp. 940 y ss.
} 
12. En la Sentencia objeto de comentario se sigue un razonamiento similar. El TJUE señala que de los términos del art. 8 del Reglamento 2201/2003, que es la norma general de competencia judicial internacional en materia de responsabilidad parental, no se deduce que su aplicación esté supeditada al requisito de que exista una relación jurídica que implique a varios Estados miembros (p. 32). Como se reconoce en el texto de la propia Sentencia, en algunas disposiciones del Reglamento 2201/2003, como son los arts. 9,10 y 15, sí se contemple que su aplicación esté supeditada a la existencia de un potencial conflicto de competencia entre órganos jurisdiccionales pertenecientes a Estados miembros (p. 33), pero no es así en relación con el art. 8, cuya interpretación es la que se suscita en esta Sentencia.

13. Los Reglamentos de carácter más reciente -Reglamento 4/2009, 650/2012, 2016/1103 y 2016/1104- se aplican con carácter general, a situaciones conectadas con Estados miembros y con terceros Estados, eliminado el papel subsidiario de las normas internas de competencia judicial internacional. El Reglamento 1215/2012, que vino a sustituir al Reglamento 44/2001, también supuso un avance en este sentido, pues se ampliaron las excepciones al requisito de que el demandado debe estar domiciliado en un Estado miembro, a efectos de aplicar sus normas de competencia judicial internacional. El Reglamento 2201/2003, que es anterior a todos ellos, presenta como característica distintiva que se aplica con carácter general, al igual que los Reglamentos más recientes, pero sin prescindir del papel subsidiario de las normas internas de los Estados miembros. Como veremos, en su art. 14 se regula la competencia residual en materia de responsabilidad parental cuando de los arts. 8 a 13 no se deduce la competencia de ningún órgano jurisdiccional de un Estado miembro, mediante una remisión a las leyes de cada Estado miembro.

14. Por otra parte, y dado que se trata de una relación jurídica conectada con un tercer Estado, en la Sentencia que estamos analizando se echa en falta alguna referencia al Convenio de La Haya de 19 de octubre de 1996 relativo a la competencia, la ley aplicable, el reconocimiento, la ejecución y la cooperación en materia de responsabilidad parental y de medidas de protección de los niños, cuya interacción con el Reglamento 22011/2003, en el ámbito de las normas de competencia judicial internacional, ha venido suscitando algunas dudas. El art 61.a) del Reglamento 2201/2003 dispone que en las relaciones con el Convenio, el Reglamento se aplicará cuando el menor afectado tenga su residencia habitual en el territorio de un Estado miembro. El Convenio de La Haya del 96, a sabiendas de que la UE tenía previsto regular esta materia, dispuso en su art. 52.2 que este Convenio no afectaría a la posibilidad, para uno o varios Estados contratantes, de concluir acuerdos sobre las materias reguladas por el mismo, respecto a niños que tuvieran su residencia habitual en uno de los Estados parte en tales acuerdos ${ }^{5}$. Del tenor de las mencionadas disposiciones resulta claro que las normas de competencia judicial internacional del Reglamento 2201/2003 priman cuando el menor tiene su residencia habitual en un Estado miembro y las del Convenio de La Haya del 96 cuando la tiene en un tercer Estado, parte del Convenio. Pero la duda surge cuando el menor tiene su residencia habitual en un tercer Estado, que no es parte del Convenio, pues en el propio Reglamento 2201/2003, y a pesar del tenor literal de su art. 61.a), se contempla la operatividad de sus normas de competencia judicial internacional en estas situaciones, concretamente en el art. $12.4^{6}$.

15. En la Sentencia objeto de comentario, en la que se discute si la residencia habitual de la menor está en el Reino Unido, lo que llevaba implícita la posibilidad de que se encontrara realmente en Bangladés, que es un Estado tercero, no parte del Convenio de La Haya del 96, podrían haberse considerado las relaciones entre ambos instrumentos. El Abogado General, Sr. H. SAugmandsGaARd ØE, se refiere al Convenio de La Haya del 96, pero simplemente para reforzar la idea de que el art. 8 del Reglamento 2201/2003 se aplica cuando el menor tiene su residencia habitual en un Estado miembro, in-

\footnotetext{
${ }^{5}$ Vid. A. Borrás, "La cláusula de compatibilidad del art. 52.2 del Convenio de La Haya de 1996 y los instrumentos comunitarios", Nuevas fronteras del derecho de la Unión Europea. Liber amicorum J.L. Iglesias Buhigues, Valencia, Tirant lo Blanch, 2012, págs. 194 y ss.

${ }^{6}$ Sobre las dudas que generan las relaciones entre estos dos instrumentos vid. A.L. Calvo Caravaca y J. Carrascosa GonzÁlez, Derecho internacional privado, Vol. II, $18^{a}$ ed., Comares, Granada, 2018, págs. 431-432; J.C. FernÁndez RozAS y S. Sánchez Lorenzo, Derecho internacional privado, $10^{\mathrm{a}}$ ed., Civitas, Thomson Reuters, 2018, págs. 395-396.
} 
dependientemente de que la relación está conectada con otro Estado miembro o con un tercer Estado (p. 24); al hilo de este argumento, y con el mismo propósito, hace una mención del art. 12.4 del Reglamento 2201/2003, que se aplica en las situaciones conectadas con terceros Estados, no parte del Convenio de La Haya del 96 (p. 25) 7 . En la Sentencia se omiten estas referencias al Convenio, pudiendo observarse no obstante que el razonamiento del TJUE se centra en las soluciones del Reglamento y en el posible recurso en este caso, en defecto de residencia habitual del menor en un Estado miembro, a su art. 14, que lo que hace es integrar con carácter subsidiario las normas internas de los Estados miembros en materia de competencia judicial internacional, como ya se ha dicho ${ }^{8}$.

\section{La jurisprudencia del TJUE sobre el concepto de residencia habitual en el marco del Reglamen- to $2201 / 2203$}

16. La residencia habitual juega un papel fundamental en los Reglamentos de la Unión Europea y en los Convenios internacionales en los que participa la Unión Europea, ya sea directamente o a través de sus Estados miembros. Sin embargo, con el fin de preservar su carácter fáctico se ha optado por no definir este concepto, dejando que sean las autoridades encargadas de aplicar cada norma las que lo concreten en función de las circunstancias del caso. En la gran mayoría de supuestos ello no tiene por qué suscitar grandes dificultades, si bien la práctica se ha encargado de demostrarnos que pueden darse situaciones complejas, en las que sí resulte difícil’.

17. En este sentido, contamos ya con un elevado número de Sentencias del TJUE, en las que ha sido necesario acudir a este organismo para que ayudase a perfilar el concepto de residencia habitual en el marco del Reglamento 2201/2003, bien para la aplicación del foro general de competencia judicial internacional en materia de responsabilidad parental (art. 8), bien para precisar si estábamos ante un supuesto de traslado o retención ilícito de menores, donde el lugar de residencia habitual del menor juega un papel fundamental (arts. 2.11 y 11). En las líneas que siguen vamos a hacer una breve presentación de los pronunciamientos ya existentes, para ver después por qué ha sido necesario plantear una nueva cuestión prejudicial y poder valorar la respuesta que a la misma da el TJUE.

18. En las sentencias que vamos a presentar se afirma, como punto de partida, que "la residencia habitual" es un concepto para el que no se ha hecho una remisión expresa al derecho de los Estados miembros a efectos de determinar su sentido y alcance, por lo que debe ser objeto de una interpretación autónoma y uniforme, que ha de hacerse teniendo en cuenta el contexto de la disposición objeto de análisis y el objetivo que con la misma se pretende alcanzar. Esta jurisprudencia ha tenido siempre muy presente para ello el Considerando 12 del Reglamento 2201/2003, donde se afirma que las normas de

\footnotetext{
${ }^{7}$ Conclusiones presentadas el 20 de septiembre de 2018, As. 393/18 PPU, UD c. XB, ECLI:EU:C:2018:749.

${ }^{8}$ En cualquier caso, estamos ante una situación de concurrencia de instrumentos internacionales que presenta una trascendencia menor, dada la gran similitud de soluciones que ofrecen ambos instrumentos. Además, en la reforma que se está preparando del Reglamento 2201/2003 sí se recoge un artículo que regula de forma más cuidada las relaciones con el Convenio de La Haya del 96, al respecto vid. J. Pirrung, “Article 61”, U. Magnus y P. Mankowski (ed.), ECPIL, European Commentaries on Private International Law, Commentary Brussels IIbis Regulation, Otto Schmidt, Köln, 2017, págs. 468-469.

${ }^{9} \mathrm{~K}$. Hilbig-Lugani ha realizado un análisis del papel tan relevante que tiene actualmente la residencia habitual en los distintos instrumentos de Derecho internacional privado relacionados con el derecho de familia y sucesiones, poniendo de manifiesto las diferencias que pueden plantearse en su concreción y que pueden estar relacionadas tanto con la materia regulada como con el aspecto de derecho internacional abordado - para la determinación de la competencia judicial internacional o la ley aplicable-, "Habitual Residence in European Family Law: the Diversity, Coherence and Transparency of a Challenging Notion", K. Boele-Woelki, N. Dethloff y W. Gephart (eds.), Family Law and Culture in Europe. Developments, Challenges and Opportunities, Intersentia, Cambridge, Antwerp, Portland, 2014, págs. 249 y ss. El papel tan relevante que tiene la residencia habitual en materia sucesoria, así como el conocimiento previo de los problemas que ya se estaban planteando, pudo ser la causa de que en el Reglamento 650/2012 sí se ofrezcan al menos pautas interpretativas para resolver situaciones difíciles (Considerandos 23 y 24), vid. J. CARrascosa GonzÁlez, "Reglamento sucesorio europeo y residencia habitual del causante", Cuadernos de Derecho Transnacional, 2016, Vol, 8, № 1, págs. 47 y ss.) Toda esta problemática está dando lugar a que surjan propuestas para superar la indefinición del concepto de residencia habitual, vid. L.A. PÉrez MARíN, "Propuesta de un concepto europeo de residencia habitual en derecho de familia internacional”, Anuario Español de Derecho Internacional Privado, t. XVIII, 2018, págs. 469 y ss.
} 
competencia judicial internacional en materia de responsabilidad parental están concebidas en función del interés superior del menor, y en particular, en función del criterio de proximidad.

19. En la Sentencia del TJCE de 2 de abril de 2009 , as. $523 / 07, \mathrm{~A}^{10}$, se sentaron unas notas configuradoras del concepto de residencia habitual, que después se han ido mantenido, con las necesarias adaptaciones en función de las peculiaridades del caso concreto, en las sentencias que se han dictado con posterioridad. Concretamente, el TJCE señaló lo siguiente: la mera presencia física del menor en un Estado miembro no puede bastar para determinar la residencia habitual del menor (p. 33); además de esa presencia física en un Estado miembro, deben tenerse en cuenta otros factores que indiquen que esa presencia no tiene en absoluto carácter temporal u ocasional, pues la residencia del menor debe deducirse de una determinada integración en un entorno social y familiar (p. 38). En la Sentencia se ofrecen a continuación una serie de factores o indicios de los que deducir esa necesaria integración: la duración, la regularidad, las condiciones y las razones de la permanencia en el territorio de un Estado miembro y del traslado de la familia a dicho Estado, la nacionalidad del menor, el lugar y las condiciones de escolarización, los conocimientos lingüísticos y las relaciones familiares y sociales del menor en dicho Estado (p. 39). Se añade que la intención de los padres de establecerse con el menor en otro Estado, y que se expresa a través de circunstancias externas, puede ser un indicio a efectos de fijar el lugar de residencia habitual (p. 40) ${ }^{11}$.

20. Con posterioridad se dictó la Sentencia del TJUE de 22 de diciembre de 2010 C497/10 PPU, Barbara Mercredi y Richard Chaffe ${ }^{12}$, que presentaba como peculiaridad, frente a la anterior, que se trataba de una menor lactante, que su madre había trasladado de un Estado miembro a otro Estado miembro. El TJUE, recordando la Sentencia anterior, volvió a insistir en la idea de que para determinar la residencia habitual del menor, además de la presencia física en un Estado miembro, deben tenerse en cuenta otros factores que puedan indicar que dicha presencia no tiene en absoluto carácter temporal $\mathrm{u}$ ocasional (p. 49). La peculiaridad en este caso, al tratarse de un menor lactante, es que para la determinación de esos indicios o factores de integración había que atender a las circunstancias de la madre, que era quien lo tenía a su cargo (p. 56).

21. En dos Sentencias posteriores se reiteraron estos mismos criterios, adaptándolos a las circunstancias del caso concreto. En la Sentencia del TJUE de 9 de octubre de 2014, C376/14 PPU, C y M ${ }^{13}$, se cuestionó si el traslado del menor, que había tenido lugar conforme a una resolución judicial ejecutiva provisionalmente, que fue revocada posteriormente por una resolución judicial que fijaba la residencia del menor en el domicilio del progenitor que permanecía en el Estado miembro de origen, encajaba en el supuesto de traslado ilícito de los arts. 2.11 y 11 del Reglamento a efectos de la tramitación de una solicitud de restitución (p. 51). El TJUE llamó la atención sobre la necesidad de considerar que ese traslado se había producido sobre la base de una resolución que tenía carácter provisional. Y por otra parte, la Sentencia del TJUE de 15 de febrero de 2017, C499/15, W, V y X ${ }^{14}$, relativa a una demanda de modificación de medidas en materia de responsabilidad parental y alimentos que se pretendía tramitar en Lituania, respecto de un menor que tenía su residencia habitual en los Países Bajos junto a su madre (p.60), donde además de reiterarse las consideraciones ya vistas sobre los elementos configuradores del concepto de residencia habitual,

${ }^{10}$ ECLI:EU:C:2009:225, nota de E. Rodríguez Pineau, en Revista española de Derecho internacional, 2009, No 1, Vol. LXI, págs.. 197 y ss.

${ }^{11}$ En la jurisprudencia de los Estados miembros se observa gran diversidad en cuanto a los factores o indicios a tener en cuenta para determinar el lugar de residencia habitual, vid. T. KRUGER, "Chapter 2. Finding a Habitual Residence", I. VIARENGO y F. C. Villata (eds.), Planning the Future of Cross-Border Families: a Path through Coordination. Final Study, págs. 79 y ss, consultado en: EUFam's Project, http://www.eufams.unimi.it/project/. En este sentido también, M.A. Gandía SelLENS, "La responsabilidad parental y la sustracción de menores en la propuesta de la Comisión para modificar el RBII bis: algunos avances, retrocesos y ausencias”, Anuario Español de Derecho Internacional Privado, t. XVII, 2017, pp. 799-820.

12 ECLI:EU:C:2010:829, nota de S. Álvarez GonZÁlez en Revista Española de Derecho Internacional, Vol. LXII, 2010, $\mathrm{n}^{\circ} 2$, págs. 251 y ss.

${ }^{13}$ ECLI:EU:C:2014:2268

${ }^{14}$ ECLI:EU:C:2017:118. Sobre esta Sentencia vid. S. Álvarez GonzÁLEZ, "Competencia judicial internacional para la modificación de sentencia en materia de responsabilidad parental y de obligaciones alimenticias. Sentencia de 15 de febrero de 2017, asunto C-499/15: W y V”, La Ley Unión Europea No 47, abril 2017, págs. 1 y ss. 
se recogen afirmaciones en el sentido de que para determinar la residencia habitual en un Estado miembro se requiere, como mínimo, que el menor haya estado presente físicamente en ese Estado miembro (p 61).

22. Resulta interesante, por el carácter novedoso de la situación que se plantea, la Sentencia del TJUE de 8 de junio de 2017 C111/17 PPU, OL y $\mathrm{PQ}^{15}$. Se trataba nuevamente de una menor lactante, que nace en un Estado miembro (Grecia), con la intención supuestamente de los progenitores, de fijar después su residencia en otro Estado miembro (Italia), que era el país donde vivía la pareja antes del nacimiento de la menor. El TJUE recordó nuevamente que la residencia habitual del menor se corresponde con el lugar en el que éste tenga una cierta integración en un entorno social y familiar (p. 42), y que para ello, además de la presencia física del menor en un Estado miembro, deben tenerse en cuenta otros factores que puedan indicar que dicha presencia no tiene en absoluto carácter temporal u ocasional ( $\mathrm{p}$. 43), con las peculiaridades ya vistas a propósito de caso Mercredi cuando se trata de un menor lactante (p. 45). Pero en este caso se reflexiona además sobre el papel que juega la intención de los progenitores, señalando, al igual que se hizo en la primera sentencia que mencionábamos, que puede ser un indicio a efectos de concretar el lugar de residencia habitual del menor, pero sin que esa intención resulte decisiva por sí sola (p. 47). Señala el TJUE que adoptar como criterio preponderante la intención inicial de los progenitores de que la madre regresase acompañada de la menor a Italia, estableciendo así una regla general y abstracta de que la residencia habitual de un lactante se corresponde necesariamente con la de sus padres, supondría ir más allá de los límites del concepto de residencia habitual en el sentido del Reglamento 2201/2003 (p. 50), que refleja esencialmente una cuestión de hecho (p. 51).

23. La Sentencia del TJUE de 28 de junio de 2018 C512/17, HR ${ }^{16}$, que es la última en esta línea de pronunciamientos previos a la Sentencia objeto de comentario, mantiene los criterios configuradores de la residencia habitual (p.41), volviendo a insistir en la idea de que al estar basada esencialmente en circunstancias objetivas, la intención de los padres no es, en principio, decisiva por sí sola a estos efectos (p. 64). Como originalidad de esta Sentencia señalar que identifica la residencia habitual del menor con el lugar en que se sitúa su centro de vida, concluyendo con una lista de circunstancias determinantes a tener en cuenta, que diferencia de otras que no lo son (p 66) ${ }^{17}$.

24. El concepto de residencia habitual ha sido ampliamente analizado a propósito del Convenio de La Haya de 25 de octubre de 1980 sobre los aspectos civiles de la sustracción internacional de menores, donde, al igual que en el marco del Reglamento 2201/2003, juega un papel fundamental a efectos de determinar que se ha producido un traslado o retención ilícitos. Tal como se ha señalado, ha habido tradicionalmente tres posturas en la jurisprudencia de los distintos Estados parte a la hora de determinar el lugar de residencia habitual del menor: una primera, que atiende al menor y a su centro de vida, considerando aspectos de carácter fáctico; una segunda, que atiende a la intención de los progenitores que cuidan del menor, considerando que son los que tienen derecho a decidir su lugar de residencia; y una tercera, denominada híbrida, que combina los dos anteriores, de forma que mantiene el énfasis en las circunstancias fácticas del menor, pero considerando también las intenciones de los progenitores ${ }^{18}$. Pues bien, de la jurisprudencia anterior puede deducirse que el TJUE, a la hora de precisar el concepto de residencia habitual en el marco del Reglamento 2201/2003, ha optado por un enfoque híbrido, que atiende a criterios fácticos, relacionados con la presencia del menor en un Estado miembro, acompañada de indicios o factores que demuestran que hay una cierta integración, sin dejar de reconocer un cierto papel a la intención de los progenitores.

\footnotetext{
${ }^{15}$ ECLI:EU:C:2017:436

${ }^{16}$ ECLI:EU:C:2018:513.

${ }^{17}$ Coincidimos con L.A. Pérez MARTín en hacer una valoración positiva de esta Sentencia, pues la concreta determinación de los factores que se consideran relevantes a efectos de fijar el lugar de residencia habitual, distinguiéndolos de los que no lo son, contribuye a facilitar la aplicación del Reglamento por los órganos jurisdiccionales nacionales, "Residencia habitual de los menores y vulneración de derechos fundamentales. Sentencia del Tribunal de Justicia de 17 de octubre de 2018, asunto C-393/18, PPU”, La Ley Unión Europea, nº 66, 31 de enero de 2019, pág. 3.

${ }^{18}$ Vid. M Ma .C. Chéliz InGLÉs, La sustracción internacional de menores y la mediación. Retos y vías prácticas de solución, Tirant lo Blanch, Valencia, 2019, págs. 46 y ss.
} 


\section{La presencia física del menor en un Estado miembro como elemento configurador del foro ge- neral de la residencia habitual}

25. En este contexto, en la Sentencia objeto de comentario se plantea la cuestión de si la presencia física de un menor en un Estado miembro constituye un elemento esencial de la residencia habitual, en el sentido del art. 8 del Reglamento 2201/2003. A la luz de la jurisprudencia reflejada en el epígrafe anterior esta cuestión, por sí sola, carecería de mucho sentido. Pero se explica en conexión con la segunda cuestión que se realiza, y que se refiere a si influye el hecho de que la madre fuera inducida supuestamente mediante engaño a trasladarse a otro Estado, en el que fue retenida ilícitamente por el padre mediante presiones u otro acto ilegal, viéndose con ello obligada a dar a luz en ese Estado, lo cual pudo provocar una vulneración de los derechos de la madre y de la menor.

26. Como pone de manifiesto el Abogado General, Sr. H. SAUGmandSGAARD ØE, esta cuestión prejudicial se formuló en el contexto de un debate jurídico más amplio. En la Supreme Court of the United Kingdom se había planteado un litigio cuyos hechos se asemejaban mucho a los controvertidos en la Sentencia objeto de análisis: asunto A v A (Children: Habitual Residence), referida al lugar de residencia habitual de un menor nacido en Paquistán, que no había estado nunca en el territorio del Reino Unido. Y en Francia la Cour de Cassation había tenido también que pronunciarse sobre el lugar de residencia habitual de un menor, en un asunto en el que una madre, que residía en Estados Unidos con el padre y el primer hijo de la pareja, había acudido a Francia, embarazada de su segundo hijo para realizar una visita temporal, decidiendo posteriormente y de forma unilateral, una vez dio a luz allí a su segundo hijo, no volver a Estados Unidos ${ }^{19}$. En definitiva, que existía la necesidad de que el TJUE arrojara algo de luz sobre cómo debía interpretarse el concepto de residencia habitual en estas situaciones, que estaban resultando muy problemáticas.

27. En este contexto, el Abogado General, Sr. H. SaugmandsGaArd ØE, propuso una interpretación, que entendemos que se apartaba y forzaba en cierta medida la línea interpretativa que había venido mantenido el TJUE en su jurisprudencia anterior, y que de hecho no fue aceptada por el Tribunal. Como es lógico, el Abogado General no desconoce que de forma reiterada la jurisprudencia del TJUE ha recurrido a la expresión "además de la presencia física [...]", antes de enumerar los factores o indicios de los que deducir que hay una cierta integración del menor en un Estado miembro y que no se trata de una presencia temporal u ocasional, pero subraya que el TJUE nunca se ha detenido específicamente en la cuestión relativa al carácter indispensable o no de tal presencia física (p. 56). Prosigue señalando, en relación con la afirmación que con tanta claridad se realizaba en la Sentencia del TJUE de 15 de febrero de 2017, C499/15, W, V y X, en el sentido de que para la determinación de la residencia habitual del menor en un Estado miembro se requiere, como mínimo, que el menor haya estado presente físicamente en ese Estado miembro, que esa Sentencia debía interpretarse a la luz de su contexto fáctico, en el que se quería restar importancia a la nacionalidad del menor como expresión de vínculo efectivo con un determinado país (p. 57). Y en relación con la Sentencia del TJUE de 8 de junio de 2017 C111/17 PPU, OL y PQ, donde se descartó que el menor tuviera su residencia habitual en Italia en base a que esa era la intención inicial de los progenitores, indica que el TJUE podía haberse limitado a poner de manifiesto que el menor nunca había estado físicamente en este país, cosa que no hizo (p. 62). El Abogado General, Sr. H. SAUGMANDSGaARD ØE, añadió, para defender su argumentación, que depender necesariamente de la presencia física a efectos de determinar el lugar de residencia habitual, supondría que este concepto perdería la flexibilidad que permite materializarlo en función del criterio de proximidad y del interés superior del menor (p. 65), flexibilidad que es especialmente necesaria cuando se trata de menores lac-

\footnotetext{
${ }_{19}$ Para más detalle sobre esta jurisprudencia vid. Conclusiones del Abogado General (cit. supra nota 7), pp. 42-44; T. KRUGER, "Chapter 2. Finding a Habitual Residence", I. Viarengo y F. C. Villata (eds.), Planning the Future of Cross-Border Families: a Path through Coordination. Final Study, op. cit., págs. 85-86; P. BEAumont y J. HolLIDAY, Recent Developments on the Meaning of Habitual Residence in Alleged Child Abduction Cases, https://www.abdn.ac.uk/law/documents/Recent_Developments_on_the Meaning_of_Habitual_Residence_in_Alleged_Child_Abduction_Cases_pdf; A. FiorINI, "Habitual Residence and the Newborn - a French Perspective", The International and Comparative Law Quarterly, 2012, Vol. 61, págs. 530 y ss.
} 
tantes, que pueden nacer y residir en un país distinto de aquel en el que sus padres tienen, a consecuencia de sus lazos familiares y sociales, el centro efectivo de sus vidas (p. 66).

28. Como hemos señalado, la Sentencia objeto de comentario no sigue este razonamiento, lo cual hay que considerar correcto. Contamos ya con un importante número de sentencias, en las que se han perfilado las notas configuradoras de la residencia habitual, como concepto autónomo y uniforme propio del Reglamento 2201/2003. Este concepto se ha construido sobre la base de la presencia física del menor, unida a una serie de factores que demuestran que no se trata de una presencia temporal u ocasional, factores que hay que determinar por referencia a la persona o personas, normalmente progenitores, que cuidan del menor cuando se trata de menores lactantes. Las Sentencias del TJUE son constantes en este sentido, a pesar de que el Abogado General quiera ahora poner el acento en aspectos puntuales de algunas de ellas para propiciar otra interpretación. El hecho de que el TJUE nunca se hubiera detenido hasta ahora en la cuestión relativa al carácter indispensable o no de la presencia física del menor en un Estado miembro, ha podido obedecer más bien a que así se ha venido sobreentendiendo, sin necesidad de decirlo expresamente. Para reforzar esta conclusión se añaden en la Sentencia consideraciones sobre la estructura general de las normas de competencia judicial internacional en el marco del Reglamento 2201/2003, diferenciando el art. 8 relativo a la residencia habitual del menor, en el sentido que hemos visto que se interpreta por el TJUE, de otras normas de competencia judicial internacional que no exigen dicha residencia (arts. 12, 13, 14 y 15, p. 56).

29. Por otra parte, tal como decíamos al iniciar este epígrafe, esta cuestión prejudicial se plantea en un contexto muy excepcional, pues hay que determinar si influye en la respuesta el hecho de que la madre, supuestamente, haya sido retenida ilícitamente por el padre en un tercer país, viéndose obligada a dar a luz a su hija en ese Estado, sin que los progenitores tuvieran la intención inicial de vivir en ese tercer país. El Abogado General, Sr. H. SAugmandSGaARD ØE, es de la opinión que en este caso la intención de la madre de no vivir en este país debe revestir una importancia particular, pues los elementos objetivos que rodean la estancia del menor y de ese progenitor en el país en el que se encuentran no son indicativos del lugar en el que estos están realmente integrados en un entorno familiar y social (p. 92). No obstante, tras referirse el TJUE a la necesaria presencia física del menor en un Estado miembro a efectos de determinar la residencia habitual, era consecuencia lógica que también se mantuviera fiel a su jurisprudencia relativa a que la intención de los progenitores puede ser un indicio a tener en cuenta, pero sin que pueda concedérsele una importancia preponderante en perjuicio de consideraciones geográficas objetivas (p. 62) ${ }^{20}$.

30. El TJUE no es ajeno a la presión que deriva de que en este caso se alega una posible vulneración de los derechos de la madre o de la menor, con referencia a los arts. 3 y 5 del Convenio Europeo para la Protección de los Derechos Humanos y de las Libertades Fundamentales, que se reproducen en los arts. 4 y 6 de la Carta de los Derechos Fundamentales de la Unión Europea. No obstante, en la Sentencia objeto de análisis se esfuerza por preservar su línea jurisprudencial anterior, sin alterarla en función de las circunstancias de este caso concreto, con un argumento con el que da una cierta impresión de pasar de forma superficial por este asunto ${ }^{21}$. Se alude a que los intereses del menor ya se han tenido en cuenta a la hora de elaborar las disposiciones del Reglamento 2201/2003 y se menciona también el papel que desempeña el art. 14 del Reglamento 2201/2003, que permite a los Estados miembros proteger los intereses de los menores mediante la atribución de competencia a sus órganos jurisdiccionales en virtud de su derecho nacional (p. 66). En concreto, en el presente asunto se alude a la posibilidad de que los tribunales del Reino Unido acudiesen a la competencia parens patriae de sus órganos jurisdiccionales,

\footnotetext{
${ }^{20}$ Como señala G. BiAgioni, frente a la tendencia de los tribunales nacionales a conceder mayor relevancia a la intención de los progenitores a efectos de fijar el lugar de residencia habitual del menor, el TJUE se ha venido oponiendo por considerar que puede afectar a la seguridad jurídica, y así se mantiene también en la Sentencia objeto de comentario, "Jurisdiction in matters of parental responsibility between legal certainty and children's fundamental rights", European Papers. European Forum, 15 April 2019, págs. 8-9.

${ }^{21}$ En este sentido L.A. PÉrez MArtín, "Residencia habitual de los menores y vulneración de derechos fundamentales. Sentencia del Tribunal de Justicia de 17 de octubre de 2018, asunto C-393/18, PPU”, op. cit., pág. 5.
} 
norma que se aplica a los ciudadanos británicos siempre que los órganos jurisdiccionales nacionales lo estimen oportuno (p. 67).

31. Pues bien, esa referencia al art. 14 del Reglamento 2201/2003, que se basa en las normas nacionales de cada Estado miembro, como posible garantía para la protección de los derechos de los menores que, como en ese caso concreto se encuentran en una situación delicada en un tercer Estado, nos lleva a llamar la atención sobre la necesidad de ser muy cuidadosos en el caso de que en un futuro se optase por incorporar foros subsidiarios. 